\title{
Correction: Niazi, A., Prasher, S.O., Adamowski, J., Gleeson, T. A System Dynamics Model to Conserve Arid Region Water Resources through Aquifer Storage and Recovery in Conjunction with a Dam. Water 2014, 6, 2300-2321
}

\section{Amir Niazi ${ }^{1, *}$, Shiv O. Prasher ${ }^{2}$, Jan Adamowski ${ }^{2}$ and Tom Gleeson ${ }^{3}$}

1 Department of Geoscience, Faculty of Science, University of Calgary, 2500 University Dr. NW, Calgary T2N 1N4, Canada

2 Department of Bioresource Engineering, Faculty of Agricultural and Environmental Sciences, Macdonald Campus of McGill University, 21111 Lakeshore Road, Sainte-Anne-de-Bellevue, QC H9X 3V9, Canada; E-Mails: shiv.prasher@mcgill.ca (S.O.P.); jan.adamowski@mcgill.ca (J.A.) 3 Department of Civil Engineering and Applied Mechanics, Faculty of Engineering, McGill University, 3450 University Street, Montreal H3A 0C3, Canada; E-Mail: tom.gleeson@mcgill.ca

* Author to whom correspondence should be addressed; E-Mail: aniazi@ucalgary.ca; Tel.: +1-403-220-8811.

Received: 22 November 2014; in revised form: 22 November 2014 / Accepted: 3 December 2014 / Published: 17 December 2014

We have recently been made aware by Prof. Sharon Megdal (The University of Arizona) and Dr. Peter Dillon (CSIRO) of some errors and omissions in our recent paper [1]. The authors wish to make the following corrections to this paper:

1. To the second to fourth paragraphs of Introduction section we made the following corrections:

a. Second paragraph, lines 3 and 4, the definition of ASR, surface water is moved to aquifers via injection wells. We deleted "infiltration, seepage or deep".

b. Third paragraph, line 2, "artificial recharge is" was modified to "managed aquifer recharge (MAR) techniques, including ASR, are"; lines 4 and 5, "ASR" was replaced by "MAR".

c. Fourth paragraph, lines 1, 2 and 5, "ASR" was replaced by "MAR". 
The corrected paragraphs, currently, read as follows:

An alternative to constructing dams is recharge enhancement [4], a technique used to increase groundwater availability. One well-known recharge enhancement technique is the engineered system of aquifer storage and recovery (ASR), whereby surface water is moved to aquifers via injection wells and serves to bolster groundwater resources. This water can later be recovered for reuse by conventional pumping. The technique was first implemented in 1957 to inject potable water into saline aquifers [5,6].

Given increasing water demand, stresses on supply and wet versus dry season water imbalances, managed aquifer recharge (MAR) techniques, including ASR, are likely to become an important component of water projects in arid and semiarid regions [7]. Aquifers offer significant opportunities for underground water storage, reducing the need of high-cost surface reservoirs and storage tanks. Applying MAR techniques can also act to restore a depleted aquifer's functionality [8]. Moreover, MAR can improve agricultural water security, thus improving the livelihood of farmers and providing economic, social and environmental benefits.

In terms of economic benefits, MAR has direct, as well as indirect financial benefits. The costs involved in MAR projects depend on several variables, including location, land prices, method of recharge, geological conditions, design of the entire holistic system, construction costs and initial water quality $[9,10]$. For two such projects in Australia, the costs of recharge per million liters were 625 USD and 2000 USD [5,11]. In addition, MAR increases agricultural productivity, which, in turn, improves farmers' livelihood and provides direct benefits, not only at the economic level, but also at the social and cultural levels. A cost benefit analysis developed for a case study in southwest Iran found a 1:1.32 ratio of project investments to agricultural profits, with an estimated payback period of three years [12].

2. Equation (4) is corrected as follows:

Original:

$$
Q_{a b}=\frac{\left(T_{a}-T_{b}\right)}{2} \cdot \Delta x \cdot \frac{\left(h_{a}-h_{b}\right)}{\Delta x}=\frac{\left(T_{a}-T_{b}\right)}{2} \cdot\left(h_{a}-h_{b}\right)
$$

Corrected:

$$
Q_{a b}=\frac{\left(T_{a}+T_{b}\right)}{2} \cdot \Delta x \cdot \frac{\left(h_{a}-h_{b}\right)}{\Delta x}=\frac{\left(T_{a}+T_{b}\right)}{2} \cdot\left(h_{a}-h_{b}\right)
$$

3. Equation (5) is corrected as follows:

Original:

$\frac{d s_{a}}{d t}=\frac{\left(T_{a}-T_{b}\right)}{2} \cdot\left(h_{a}-h_{b}\right)+\frac{\left(T_{a}-T_{c}\right)}{2} \cdot\left(h_{a}-h_{c}\right)+\frac{\left(T_{a}-T_{d}\right)}{2} \cdot\left(h_{a}-h_{d}\right)+\frac{\left(T_{a}-T_{e}\right)}{2} \cdot\left(h_{a}-h_{e}\right)+Q_{a B}$

Corrected:

$\frac{d s_{a}}{d t}=\frac{\left(T_{a}+T_{b}\right)}{2} \cdot\left(h_{a}-h_{b}\right)+\frac{\left(T_{a}+T_{c}\right)}{2} \cdot\left(h_{a}-h_{c}\right)+\frac{\left(T_{a}+T_{d}\right)}{2} \cdot\left(h_{a}-h_{d}\right)+\frac{\left(T_{a}+T_{e}\right)}{2} \cdot\left(h_{a}-h_{e}\right)+Q_{a B}$ 
4. Reference [5] is corrected as follows:

Original:

5. Khana, S.; Mushtaqb, S.; Hanjraa, M.A.; Schaefferd, J. Estimating potential costs and gains from an aquifer storage and recovery program in Australia. Agric. Water Manag. 2008, 95, 477-488.

Corrected:

5. Khan, S.; Mushtaq, S.; Hanjra, M.A.; Schaeffer, J. Estimating potential costs and gains from an aquifer storage and recovery program in Australia. Agric. Water Manag. 2008, 95, 477-488.

Please refer to the supplementary for the corrected paper. The authors would like to apologize for any inconvenience caused to the readers by these changes.

\section{Reference}

1. Niazi, A.; Prasher, S.O.; Adamowski, J.; Gleeson, T. A System Dynamics Model to Conserve Arid Region Water Resources through Aquifer Storage and Recovery in Conjunction with a Dam. Water 2014, 6, 2300-2321.

(C) 2014 by the authors; licensee MDPI, Basel, Switzerland. This article is an open access article distributed under the terms and conditions of the Creative Commons Attribution license (http://creativecommons.org/licenses/by/4.0/). 